www.periodicos.unimontes.br/index.php/caminhosdahistoria

\title{
APONTAMENTOS SOBRE A RELAÇÃO 'COR DA PELE/CIDADANIA' NAS CONSTITUIÇÕES DA VENEZUELA (1811) E DO BRASIL (1824)
}

Iara de Oliveira Maia ${ }^{1}$

Resumo: Neste artigo debatemos sobre a primeira Constituição Imperial do Brasil, outorgada em 1824, onde focamos especialmente a revogação da "mancha de sangue" contra indivíduos de cor, uma vez que passou a considerar como cidadãos brasileiros todos os homens livres nascidos no Brasil, independente da cor da pele. Também analisaremos a primeira Constituição Federal da Venezuela, promulgada em 1811, principalmente a revogação de todas as leis que impunham a degradação civil a uma parte da população livre da Venezuela, denominada de pardos, que passaram a ter direitos de cidadãos. Assim, a partir dos artigos das duas Constituições, procuramos analisá-las no que diz respeito à presença ou não da questão da cor da pele nos seus textos, e no que se refere à extensão da cidadania e dos direitos e deveres de seus cidadãos.

Palavras-chave: Constituição de 1811; Venezuela; Constituição de 1824; Brasil; cor da pele; cidadania.

Abstract: In this article we discuss about the first Imperial Constitution of Brazil, granted in 1824, when we focused especially on the revocation of the "blood stain" against individuals of color, since it started to consider as Brazilian citizens all free men born in Brazil, regardless of skin color. We will also analyze the first Federal Constitution of Venezuela, enacted in 1811, mainly the repeal of all laws that imposed civil degradation on a part of Venezuela's free population, called "pardos", who now have citizens' rights. Thus, from the articles of the two Constitutions, we seek to analyze them with regard to the presence or absence of the skin color issue in their texts, and with regard to the extension of citizenship and the rights and duties of their citizens.

Keywords: Constitution of 1811; Venezuela; Constitution of 1824; Brazil; skin color; citizenship.

Refletir sobre a construção da cidadania no Oitocentos implica em considerar o longo caminho percorrido pelo fenômeno da cidadania nas Américas e no Brasil, abrangendo as dimensões em que fora estabelecida, bem como as tensões e conflitos sociais que marcaram seu percurso (CARVALHO, 2002). A historiografia sobre essa temática destaca que é fundamental conceber a cidadania de maneira ampla, uma vez que ser cidadão no século XIX não era entendido de uma única forma. Tratava-se de um contexto em que as ideias de liberdade e igualdade entre os cidadãos estavam sendo difundidas nos processos de independência dos países americanos. Sendo assim, é preciso pensar o âmbito da cidadania

\footnotetext{
${ }^{1}$ Iara de Oliveira Maia. Mestre, licenciada e bacharel em História pela Universidade Federal de Ouro Preto (UFOP). E-mail: iaramaia_ufop@yahoo.com.br. ORCID: https://orcid.org/0000-0002-4762-4836.
} 
relacionado ao Estado e suas instituições, como também relacioná-lo à esfera pública, já que a partir de tais processos um número considerável de cidadãos passou a pertencer a um corpo político e à sociedade civil.

A historiografia ${ }^{2}$ têm enfatizado a importância de se pensar os temas nacionais como fazendo parte de um conjunto mais amplo, para não se dissociar o local do global, e de se estabelecer um diálogo, um olhar comparativo em um âmbito regional e inter-regional. Mas também chamam a atenção para o cuidado que se deve ter neste sentido, para não correr o risco de não simplificar a complexidade das experiências, para não se exagerar as semelhanças e diferenças, etc.

Deste modo, este artigo busca apontar algumas características semelhantes e/ou divergentes entre as primeiras experiências constitucionais de dois países, Venezuela e Brasil. Ressaltamos que não pretendemos realizar uma síntese dessas experiências, que apesar de fazerem parte de um mesmo continente, estiveram inseridas em contextos diferentes nos processos de elaboração de suas constituições. Neste artigo, voltamos nossa atenção para a primeira Constituição Imperial do Brasil, outorgada em 1824, focalizando especialmente a revogação da "mancha de sangue" contra indivíduos de cor, uma vez que passou a considerar como cidadãos brasileiros todos os homens livres nascidos no Brasil, independente da cor da pele. Também analisaremos a primeira Constituição Federal da Venezuela, promulgada em 1811, principalmente a revogação de todas as leis antigas que impunham a degradação civil a uma parte da população livre da Venezuela, denominada de pardos, que passaram a ter direitos de cidadãos. Assim, a partir destes artigos das duas Constituições, procuramos analisá-las no que diz respeito à presença ou não da questão da cor da pele em seus textos, e no que se refere à extensão da cidadania e dos direitos e deveres dos cidadãos ${ }^{3}$.

\footnotetext{
${ }^{2}$ Sobre estudos que realizam uma abordagem comparativa: GREENE \& MORGAN, 2009; MARQUESE; PARRON \& BERBEL, 2010; SABATO, 2009.

${ }^{3}$ Enquanto o Brasil e a Venezuela foram colônias, respectivamente, de Portugal e Espanha, vigorou em seus contextos as legislações de suas metrópoles. A expansão do Império português, no período colonial, trouxe transformações para a sociedade portuguesa no que diz respeito ao alargamento das hierarquias sociais na estratificação social. Devido ao contato com outros povos, foi preciso integrar os novos elementos, como os índios e os africanos, ao corpo do Império. Numa concepção corporativa de sociedade, esses indivíduos foram compreendidos como fracos, carentes de proteção e educação e os africanos ainda foram vistos como os mais bárbaros e incivilizados, integrando a categoria dos de "inferior condição", marcados pela "mancha de sangue". Uma pessoa de "sangue infecto" era automaticamente uma pessoa de "ínfima condição", na mais baixa posição social (LARA, 2007). Além disso, Mattos ressalta que através do conceito de "limpeza de sangue" que se determinavam as diferenciações e se definia o lugar social dos mouros, judeus, ameríndios ou africanos, oferecendo restrições diversas a esses indivíduos e seus descendentes. Foi nessa lógica societária em que ocorreu a incorporação dos escravos africanos e dos forros e seus descendentes, para os quais, mesmo enquanto descendentes de libertos por pelo menos quatro gerações, estaria vedado o acesso aos altos cargos públicos e eclesiásticos, bem como às honrarias reservadas aos cristãos-velhos. A ascendência africana/escrava foi diretamente relacionada com a concepção de "sangue impuro", passando a integrar os estatutos de "pureza de sangue": "o estatuto de pureza de sangue, apesar de sua base religiosa, construía, sem dúvida, uma
} 
É importante destacar que nos contextos escravistas do continente americano, a cor da pele estava diretamente relacionada à condição escrava (MATTOS, 2000). Neste sentido, alguns designativos de cor foram utilizados em determinadas situações para demarcar a proximidade ou o afastamento dessa condição ${ }^{4}$. Nos casos do Brasil e da Venezuela, a relação cor da pele e escravidão permeou o processo da definição da cidadania, contribuindo para estabelecer quem seria considerado, ou não, cidadão em tais contextos.

A Venezuela e o Brasil estiveram inseridos em contextos distintos nos momentos da aprovação de suas constituições. A promulgação da Constituição de 1811 da Venezuela fez parte do processo de legitimação da independência das Províncias Unidas da Venezuela, com a tentativa de instaurar uma República, o que não ocorreu naquele momento, uma vez que a Venezuela só conseguiu sua total independência em 1821. A outorga da Constituição de 1824 do Brasil também fez parte do processo de independência, mas foi outorgada num momento em que, nas letras da lei, o país já tinha conquistado sua independência política em 1822, optando pelo regime monárquico de governo.

Mas apesar das grandes diferenças entre a opção republicana e a nossa opção monárquica, de acordo com Miriam Dolhnikoff, é possível alguma comparação,

na medida em que repúblicas e monarquias constitucionais no XIX eram variações de governos representativos, modelos surgidos na Europa e Estados Unidos na transição do XVIII para o XIX e que tinham em comum o estabelecimento de novas relações entre Estado e sociedade, com a inclusão na participação política de setores antes dela alijados (DOLHNIKOFF, 2009, p. 42).

\section{A Constituição de 1811 da Venezuela}

A promulgação da Constituição de 1811 da Venezuela fez parte do processo de conquista da independência do país, que por sua vez esteve inserido no contexto de crise do império espanhol, culminando na independência de vários países na América espanhola. Como afirma Clément Thibaud: "la consecuencia más espectacular del derrumbamiento do imperio español fue el nacimiento de una decena de repúblicas independientes (...), la transformación de la monarquía española en estados-nación marcó una ruptura, según reconocieron los mismos actores" (THIBAUD, 2007, p. 186).

estigmatização baseada na ascendência, de caráter proto-racial, que não era usada para justificar a escravidão, mas antes para garantir os privilégios e a honra da nobreza, formada por cristãos-velhos, no mundo dos homens livres" (MATTOS, 2001, p. 149). Ou seja, pode-se afirmar que o estigma da "mancha de sangue" se revestiu de novos significados a partir da experiência colonial, sobretudo, em função da expansão da sociedade escravista. Sobre os critérios de pureza de sangue presentes na legislação espanhola, ver: GÓMEZ, 2005; 2008.

${ }^{4}$ Para o debate historiográfico sobre os usos e significados dos designativos de cor durante os períodos colonial e imperial, conferir capítulo 1 de minha dissertação: MAIA, 2012. 
Conforme Thibaud (2007) e Sabato (2009), um dos principais fatores que levaram à crise do império espanhol foi a invasão da Espanha por Napoleão em 1808, e a prisão de Fernando VII em Valencia. Esta invasão, que gerou um vazio de poder e a instauração de uma Junta para reforçar o controle sobre as províncias, trouxe para a América espanhola discussões sobre o princípio da "soberania popular", que se baseava na questão de que na ausência do rei, ocorria a "reversão da soberania ao povo", princípio este que foi adotado em quase todas as tentativas de conformação de novas comunidades políticas depois da ruptura da ordem monárquica espanhola. Como afirma Sabato:

Uma vez caída a monarquia e desmontado o império espanhol - o que incluía seus domínios americanos - a reconstrução da ordem política foi sendo tentada sob o princípio da soberania popular junto com a necessidade de dar forma às comunidades - "nações" - novas que, além disso, deviam ser a fonte de poder soberano e espaço de exercício desse poder (SABATO, 2009, p. 7).

Ou seja, segundo tais autores, as Américas, com a única exceção do Brasil, voltaramse para as formas republicanas de governo, e quase todas as regiões tentaram seguir o princípio da "soberania popular". A opção pelas repúblicas constitucionais veio também tentar legitimar questões que já vinham sendo discutidas, como em torno da extensão da cidadania aos habitantes de cada território ${ }^{5}$. Para Sabato (2009), a adoção da instituição da cidadania "implicava a criação de um universo abstrato de iguais que usufruíam dos mesmos direitos (e obrigações) nas novas repúblicas em formação, como também uma ruptura com os critérios que tinham caracterizado a ordem político-social da colônia" (SABATO, 2009, p. 8). Mas vale destacar que, na prática, estes processos foram complexos e afetaram a todos e a cada um dos habitantes das terras americanas, e nenhum destes processos teve um sucesso imediato ou fez um caminho linear, ou foi feito sem ambiguidades.

No caso da Venezuela, os acontecimentos que marcaram o processo de independência e a elaboração da primeira Constituição do país tiveram suas características próprias. Inserido no contexto de crise do império espanhol, de acordo com Inés Quintero ${ }^{6}$, o vazio de poder devido à prisão do rei Fernando VII foi um dos principais fatores do processo de independência do país. Negaram em aceitar a Regência composta na península para governar as colônias, se baseando na questão de que com o rei ausente a soberania recaía sobre a nação. Por isso, segundo Quintero, “foi constituída a Junta Suprema de Caracas, depositária

\footnotetext{
${ }^{5}$ Como observado por Chiaramonte (2009), em muitas experiências constitucionalistas americanas as identidades são dadas a partir do território, ou seja, se constitui cidadão a partir dos vínculos (seja por nascimento e/ou naturalização) com o território.

${ }^{6}$ Sobre aspectos políticos e sociais específicos do processo de independência da Venezuela, ver: QUINTERO, 2009.
} 
provisória da soberania, até que se reunisse um Congresso Geral que seria o depositário legítimo da soberania" (QUINTERO, 2009, p. 120).

Mas ainda de acordo com a autora, mesmo que a princípio não tivessem como propósito romper os vínculos da província com a península, "rapidamente o movimento juntista iniciado em 19 de abril de 1810 transformou-se em independentista e, em 5 de julho de 1811, o Congresso Geral da Venezuela declarou a independência" (QUINTERO, 2009, p. 120-121). Como também afirma Clémente Thibaud, “el la temprana fecha de 1811, ya algunas provincias de la Nueva Granada se dieron una forma republicana de gobierno; en la misma fecha, las Provincias Unidas de Venezuela proclamaron su independencia del Estado, la Corona y el rey españoles" (THIBAUD, 2007, p. 186).

Obviamente, não foi apenas a ausência do rei no poder o que impulsionou o processo de independência. Podemos citar, conforme Inés Quintero, outros fatores que também justificavam a determinação independentista, como:

a política reformista dos Bourbons, cujo objetivo era reforçar os mecanismos de controle sobre as províncias; o repúdio, por parte da Coroa, à solicitação dos crioulos de liberar o comércio; a supremacia administrativa dos funcionários peninsulares sobre os crioulos; os seguidos conflitos de competência e de autoridades peninsulares; o visível incômodo criado entre os crioulos em razão da aprovação e aplicação da Real Cédula de Gracias al Sacar (Decreto Real) a favor da ascensão social dos pardos, foram as razões diretas dos acontecimentos ocorridos em 19 de abril de 1810 (QUINTERO, 2009, p. 115).

Também é importante ressaltar que, de acordo com Quintero (2009) e Alejandro Gómez (2005), todo o processo de independência até 1811 foi conduzido principalmente pelos setores privilegiados da sociedade, especialmente os brancos crioulos (filhos de europeus, nascidos na América). $\mathrm{O}$ projeto de independência não contou em um primeiro momento com o apoio majoritário da população composta, segundo os autores, entre $40 \%$ e $60 \%$ de pardos. A grande parte da "população de cor", além dos pardos, formada também por zambos, negros e mulatos, a princípio lutaram para defender a causa do rei, só no fim do processo de independência que os republicanos conseguiram o apoio da "população de cor".

Mas havia uma "elite de cor" que participou da luta pela independência, os chamados "pardos beneméritos", para tentar se igualarem aos brancos, como afirma Gómez (2005),

los sectores más prósperos y blanqueados de ese sector etno-social (los 'pardos beneméritos' venezolanos') quisieron aprovechar las conjunturas revolucionarias no para procurar una declaración universal favorable de los esclavos africanos o sus descendientes libres de 'color quebrado' o 'sangre mezclados', seno para igualarse jurídica y políticamente con los 'blancos criollos' en marco de la nueva ciudadanía basada en principios censitarios. De esta forma pretendían acabar con las distinciones basadas en el concepto 
de 'calidad', pero manteniendo la estructura social de la colonia y el sistema esclavista (p. 6).

Conforme o autor, os indivíduos pardos na Venezuela pareciam ser um grupo bem definido entre os contemporâneos, pois "la condición de pardo estaba restringida a los hombres de color con ascendencia europea, quedando fuera las "castas" y todas aquellas personas que, a pesar de estar emparentados con blancos, se habían vinculado nuevamente con negros" (GÓMEZ, 2005, p. 4). E o 'grupo' dos chamados “pardos beneméritos”, parecia ter forte influência, uma vez que a Constituição de 1811 revogou todas as leis antigas que impunham impedimentos aos pardos, como pode-se perceber no artigo 203 do Capítulo Nono:

Del mismo modo quedan revocadas y anuladas en todas sus partes, las leyes antiguas que imponían degradación civil a una parte de la población libre de Venezuela, conocida hasta ahora bajo la denominación de pardos: éstos quedan en posesión de su estimación natural y civil y restituidos a los imprescriptibles derechos que le corresponden como a los demás ciudadanos (Constitución, 1811).

A Constituição de 1811 foi promulgada como uma tentativa de legitimar a independência e de estabelecer algumas normas na nova república, como afirma Quintero (2009): “a Constituição de 1811 estabeleceu como forma de Estado a Federação, sancionou a separação de poderes, fixou um sistema eleitoral pelo voto, consagrou a liberdade, a igualdade, o direito à propriedade e à segurança, eliminou os foros e privilégios e proclamou o nascimento da República" (p. 121). Contudo, a autora também ressalta que "a aprovação desta primeira Carta Magna não provocou imediatamente uma mudança na sociedade nem na maneira de conduzir seus indivíduos” (Quintero, 2009, p. 121).

É interessante pensar alguns pontos da Constituição de 1811 a partir do artigo que revogou as leis que impunham impedimentos aos pardos, uma vez que o texto também procurava enfatizar a igualdade de todos, como se vê no artigo 152 da "Sección segunda. Derechos del hombre en sociedad": "Estos derechos son la libertad, la igualdad, la propiedad y la seguridad". E no artigo 154 da mesma seção define igualdade: "La igualdad consiste en que la ley sea una misma para todos los Ciudadanos, sea que castigue o que proteja. Ella no reconoce distinción de nacimiento, ni herencia de poderes" (Constitución, 1811).

Percebe-se que a extensão da cidadania especificamente ao grupo dos denominados pardos refletia a importância socioeconômica dos mesmos na sociedade venezuelana, especialmente dos denominados "pardos beneméritos". Refletia também a influência da noção de cidadania relacionada ao ideal naturalizado na época de uma sociedade desigual, que, por 
um lado agregava grande parte da população à sociedade civil, mas por outro, restringia o acesso aos direitos políticos.

Neste sentido, a noção de cidadania ativa e passiva passou a fazer parte do contexto venezuelano, assim como mais tarde no Brasil. Os cidadãos passivos seriam aqueles que teriam garantido os seus direitos civis, e os cidadãos ativos teriam os direitos civis e políticos, esses últimos garantidos pelo critério censitário (Declaración, 1811).

A primeira Constituição venezuelana considerava como cidadão todo homem livre nascido no país (Constitución, 1811). Em relação ao exercício dos direitos políticos ficava condicionado a algumas características como ser livre, possuir uma determinada renda, como se vê no artigo 26 da "Sección segunda. Elección de la Cámara de Representantes":

Todo hombre libre tendrá derecho de sufragio en las Congregaciones Parroquiales, si a esta calidad añade la de ser Ciudadano de Venezuela, residente en la Parroquia o Pueblo donde sufraga: si fuere mayor de veintiún años, siendo soltero o menor siendo casado y velado y si poseyere un caudal libre del valor de seiscientos pesos en la Capitales de Provincia siendo soltero y de cuatrocientos siendo casado, aunque pertenezcan a la mujer o de cuatrocientos siendo en las demás poblaciones en el primer caso y doscientos en el segundo; o si tuviere grado, u aprobación pública en una ciencia o arte liberal o mecánica; o si fuere propietario o arrendador de tierras, para sementeras o ganado con tal que sus productos sean los asignados para los respectivos casos de soltero u casado (Constitución, 1811).

E ainda colocava a cargo dos Cabildos realizar um censo para definir em cada localidade quem teria o direito a voto, como se vê no artigo 35 da "Sección segunda. Elección de la Cámara de Representantes":

La falta actual que hay del registro civil ordenado por el Artículo anterior para establecer las calificaciones de los Ciudadanos, podrá suplirse autorizando los Cabildos a los mismos que nombren para presidir las Asambleas primarias o parroquiales para formar un censo en cada Parroquia con vista del último formado para el actual Congreso y del Eclesiástico autorizado por el Cura o su Teniente y cuatro vecinos honrados, padres de familia y propietarios del Pueblo, que bajo juramente testifiquen tener los comprehendidos en el censo las calidades requeridas para ser sufragantes o electores (Constitución, 1811).

Além de definir os critérios censitários que estabeleciam quem teria acesso aos direitos políticos, a Constituição de 1811 também se preocupou em deixar claro quem estava excluído desse direito, como se vê no artigo 27:

Serán excluidos de este derecho los dementes, los sordomudos, los fallidos, los deudores a caudales públicos con plazo cumplido, los extranjeros, los transeúntes, los vagos públicos y notorios, los que hayan sufrido infamia no purgada por la Ley, los que tengan causa criminal de gravedad abierta y los que siendo casados no vivan con sus mujeres, sin motivo legal (Constitución, 1811). 
A Constituição seguia o princípio que, de acordo com Miriam Dolhnikoff (2009), predominava nas Américas no século XIX de que "era preciso garantir a qualidade dos representantes, de modo que homens devidamente qualificados chegassem ao parlamento habilitados para decidir de acordo com os "verdadeiros interesses nacionais"” (p. 42).

Dessa forma, chama atenção o fato de que, ao definir os considerados cidadãos, a Constituição venezuelana fez referência direta ao critério de cor da pele ao mencionar os pardos, mas não se referiu à população branca, nem ao restante da população de cor livre.

Supõe-se que a não referência aos brancos se deu porque em uma sociedade escravista, quem era branco já era livre e considerado cidadão. A consideração dos pardos como cidadãos foi, conforme Inés Quintero (2009) e Alejandro Gómez (2005), uma clara concessão de privilégio aos "pardos beneméritos", já que estes além de se reconhecerem e serem considerados pelos brancos como diferentes do restante da população de cor, possuíam renda suficiente para exercerem seus direitos políticos.

Em relação ao restante da população de cor livre, subentende-se que eram considerados cidadãos do ponto de vista dos direitos civis, mas não teriam acesso aos direitos políticos. Talvez até mesmo os que possuíssem a renda exigida não pudessem participar, uma vez que não há no texto constitucional uma referência específica a eles. Outra questão que contribui para esse apontamento está no fato de que entre os excluídos dos direitos políticos foram citados "los que hayan sufrido infamia no purgada por la Ley" (Constitución, 1811). Ou seja, enquanto a região da Venezuela foi colônia da Espanha, vigorava a legislação imposta pela metrópole, a qual baseava-se nos critérios de pureza de sangue que compreendiam as pessoas de cor como de ínfima condição, como afirma Alejandro Gómez (2005, p. 1):

las rígidas normativas coloniales basadas en el concepto de 'calidad', que determinaban -en forma quizá más formal en el caso hispano- el estatus legal que cada quien tenía dentro de las sociedades coloniales, les impedían deslastrase por completo de la "vileza" de su origen, lo que les hacía susceptibles a seguir siendo considerados -desde la perspectiva de los blancos- meramente como 'gente de color'.

Neste sentido, observamos que houve uma preocupação explícita em excluir essa parcela da sociedade do exercício dos direitos políticos, mas não da concepção dos direitos civis. Talvez essa preocupação demonstre a compreensão de que a população de cor livre tinha uma grande importância social, econômica e política para a região, sendo fundamental inclusive para o processo de independência, pois, como afirma Luiz Silva, foram eles, em 
grande parte, que tomaram atitudes enfáticas em favor da igualdade política, as quais levaram, no limite, à ruptura com a configuração abrangente do Império Espanhol: "a igualdade política de afrodescendentes livres e libertos constituiu objeto de discussões e contestações, forjando um campo de tensões que envolvia antigos outsiders e estabelecidos, ou indivíduos e grupos sociais dos níveis mais baixo e mais alto" (Silva, 2015, p. 622).

Outra preocupação estava no fato de que também constituíam a maior parte da população em Caracas (Gómez, 2008), assim como na capitania geral da Venezuela (Silva, 2015). Excluí-los totalmente da cidadania poderia estimular conspirações e revoltas em busca de liberdade e direitos, assim como havia ocorrido na ex-colônia francesa de Saint-Domingue (Gómez, 2005), abalando o sistema escravista na região ${ }^{7}$.

Diferente da Constituição do Brasil, que considerou os libertos nascidos no país como cidadãos, a Constituição venezuelana não mencionou os libertos em sua definição de cidadania. Apesar de também se basear na relação nascimento e território para definir os cidadãos venezuelanos, no tocante aos libertos não é possível afirmar com clareza se os que fossem nascidos no país seriam considerados cidadãos, pelo menos do ponto de vista dos direitos civis. Em relação aos diretos políticos, caso fossem cidadãos, não poderiam ter acesso uma vez que, possivelmente, estariam entre os excluídos que sofriam infâmia.

No Brasil, a inclusão dos libertos como cidadãos refletia a compreensão da importância social desse grupo, bem como a preocupação dos deputados e da elite em não abalar sistema escravista (MARQUESE; BERBEL, 2007). Tal inclusão fazia com que, num contexto escravagista, a liberdade individual se tornasse ainda mais atraente, pois uma vez livre o indivíduo poderia ser considerado cidadão, e assim possuidor de direitos (SLEMIAN, 2005). Ou seja, compreendiam que dessa forma se conquistaria uma estabilidade para o país. Já no caso venezuelano a estabilidade foi buscada através da opção pelo silenciamento em relação aos libertos e livres de cor. Foi uma forma de se evitar a radicalização das ideias de liberdade e igualdade. A exclusão dos livres de cor da cidadania política também demonstrava a existência de diferenças entre os próprios indivíduos de cor, o que já vinha marcando esse contexto desde pelo menos o final do século XVIII, pois como afirma Alejandro Gomez (2008):

Había marcadas diferencias clasistas y estamentales que también afectaron el desarrollo de los acontecimientos. Éstas eran particularmente intensas entre la elite de los Pardos y el resto de la población de color (Negros Libres,

\footnotetext{
${ }^{7}$ Segundo Alejandro Gómez (2005; 2008), desde o final do século XVIIII na região venezuelana ocorriam manifestações embasadas no ideal de "igualdade", com grande participação de homens livres de cor. Contribuíram para essas manifestações a difusão das ideias que chegavam principalmente da Europa a respeito de igualdade e cidadania, bem como as manifestações nas Antilhas francesas.
} 
Zambos, etc.). Los Pardos Beneméritos (como en ocasiones se llamaban a sí mismos los miembros de aquella elite) eran individuos que gozaban de un alto nivel socio-económico, con patrimonios que si bien no alcanzaban en cuantía y valor a los de los Mantuanos (elite criolla blanca), si llegaban a ser superiores a los de los Blancos de Orilla. Esta prosperidad material les había facilitado uniones con Blancos por lo que eran también eran los más "blanqueados" entre los Libres de Color. El estatus superior que detentaban en lo alto de la escala etno-estamental dentro de los sectores de color libres, era celosamente protegido mediante prácticas endogámicas, al mismo tiempo que procuraban evitar uniones conyugales con individuos considerados por ellos como inferiores" (Gomez, 2008, p. 5).

Entretanto, o fato é que em nenhum dos casos - nem no Brasil, nem na Venezuela -, as decisões constitucionais evitaram que os livres de cor continuassem a buscar por mais direitos, se manifestando em vários âmbitos e de diversas formas (AZEVEDO, 2005; MATTOS, 2000). Como afirma Luiz Silva, nos primeiros anos após a promulgação da Constituição da Venezuela, a demanda por igualdade política se fez presente em variadas representações produzidas por afrodescendentes livres e libertos:

Os "Libros de bautismo de pardos y morenos" (...) relativos aos anos de 1811 a 1819, por exemplo, contém inúmeros registros de pais, mães, padrinhos e madrinhas cujos nomes eram procedidos por "cidadão" e "cidadã", numa clara alusão à nova condição dos indivíduos daquele grupo social na sociedade de tipo democrático e representativo em formação (SILVA, 2015, p. 621).

Importante destacar que os índios foram considerados cidadãos pela Constituição de $1811^{8}$. Mas em relação aos direitos políticos, não há referência aos mesmos no texto constitucional. Supõe-se que, assim como os livres de cor e os libertos, eles fossem compreendidos entre os que sofriam infâmia, e por isso não poderiam ter acesso a esses direitos. Vale ressaltar que também foram considerados cidadãos os estrangeiros naturalizados, os quais poderiam exercer os direitos políticos se possuíssem a renda exigida (CONSTITUCIÓN, 1811). Logo, estavam excluídos do direito de ser cidadão venezuelano as mulheres, os escravos e possivelmente os libertos.

Portanto, a relação cor da pele/cidadania não foi uma questão fácil de resolver em termos constitucionais em outras sociedades escravistas no século XIX, marcadas por uma grande população de cor. Assim também foi o caso do Brasil, onde a grande população de cor tornava difícil a tarefa de fazer separações ou defini-los como um grupo homogêneo, havendo ainda a preocupação de se ver abalado o sistema escravista se se concedessem cidadania à população de cor.

\footnotetext{
${ }^{8}$ Conferir Capítulo Nono, Artigo 200: CONSTITUCíON, 1811.
} 


\section{A Constituição de 1824 do Brasil}

Durante as primeiras décadas do século XIX, no contexto de construção da cidadania no Império, o Brasil possuía uma grande parte de sua população formada por escravos e descendentes livres desses indivíduos: forros, libertos e livres (MATTOS, 2000). Diante da importância social dessa parcela da população e em meio à difusão das ideias de liberdade e igualdade, a solução encontrada foi a incorporação de todos os homens livres no universo dos cidadãos na Constituição de $1824^{9}$. Não foram estabelecidas distinções entre os indivíduos como, por exemplo, diferenciações baseadas no critério da cor da pele/racial. Diferentemente do que acontecia na América portuguesa, em que a legislação colonial se baseava nas diferenças entre as pessoas e estabelecia critérios de distinção em relação aos indivíduos de cor, em função da herança do "sangue negro". Assim, a construção da cidadania no século XIX buscou, pela ótica jurídica, não estabelecer diferenças que levassem em consideração a cor da pele dos indivíduos.

Como se percebe, a outorga da Constituição de 1824 no Brasil esteve imersa no complexo contexto de emancipação do país, inserido no contexto de crise do Império português. Conforme Andréa Slemian, os Impérios Ibéricos estiveram inseridos numa crise em condições semelhantes, mas viveriam experiências constitucionais em tempos e modos distintos, em contextos diferentes, pois, para a autora,

os desdobramentos imediatos causados pelo avanço napoleônico na Europa do início do século XIX marcariam uma separação entre seus caminhos: de um lado, a prisão do monarca e acefalia do poder nos territórios espanhóis; de outro, a vinda da Família Real para o Rio de Janeiro e a preservação imediata da dinastia bragantina e do próprio regime português (SLEMIAN, 2009, p. 21).

Foi a partir, e inserido nesta conjuntura, que se desenvolveu o processo de independência do país e a elaboração da Constituição de 1824. A idéia de um Estado brasileiro foi sendo gestada num contexto de acirrada luta política, e a legitimação desse Estado passaria por um processo de adesão das províncias:

o projeto de Independência do Brasil, mesmo sem ser unanimidade, propôs a incorporação do conjunto das Províncias portuguesas. Seu aparecimento era a prova mais cabal do esgotamento da possibilidade de consenso entre os interesses dos diversos grupos surgidos de um e de outro lado do hemisfério,

\footnotetext{
${ }^{9}$ Segundo Marquese e Berbel (2007), essa parcela da população era de grande importância para o Império. Além de a escravidão ter sido a base da economia, os indivíduos de cor livres também eram fundamentais para o aspecto econômico e para o povoamento, além de participarem dos conflitos pela independência, tendo uma atuação efetiva na vida do Império.
} 
e do qual resultaria a desagregação da estrutura imperial lusitana na América. Desde então, o pretendido Império independente encontrar-se-ia diante do nevrálgico, e idêntico, problema da criação de um regime sob a égide constitucional, com o agravante da inexistência prévia de uma articulação interna entre suas partes que lhe assegurasse a unidade "Brasil". Essa, como também se sabe, demoraria anos para se concretizar (SLEMIAN, 2009, p. 18).

Assim, a opção pelo regime monárquico constitucional de governo tentaria assegurar esta idéia de um Estado brasileiro, como afirma a autora:

o projeto de Independência do Brasil, assentado sobre as bases de uma monarquia constitucional (...), teria diante de si um fundamental desafio: inventar uma legitimidade para um novo regime que estivesse afinada com os ideais de separação e controle dos poderes políticos e com a garantia de direitos dos cidadãos (SLEMIAN, 2007, p. 35).

Neste contexto, foi outorgada a primeira Constituição Imperial do Brasil em $1824^{10}$, que ficou em vigor durante todo o período imperial, contribuindo para estabelecer as bases da estrutura política, do funcionamento do Império brasileiro e de sua população, num momento em que, segundo Hebe Mattos (2000), com a emancipação política do país se definiu pela primeira vez uma "cidadania brasileira".

A Constituição de 1824 se destacou, dentre outros fatores, ao revogar o dispositivo colonial da "mancha de sangue" contra indivíduos de cor, uma vez que passou a considerar como cidadãos brasileiros todos os homens livres nascidos no Brasil, como se pode perceber no “Artigo 6. São Cidadãos Brazileiros" do "Título 2. Dos Cidadãos Brazileiros": "I. Os que no Brazil tiverem nascido, quer sejam ingenuos, ou libertos, ainda que o pai seja estrangeiro, uma vez que este não resida por serviço de sua Nação" (CONSTITUIÇÃO, 1824).

Conforme Rafael Marquese e Márcia Berbel (2007), é importante destacar que os deputados constituintes, no processo de elaboração da Constituição, não recorreram a designativos como pardo, cabra, mulato e negro, nem a fundamentos raciais e nem às relações escravistas, para definir a cidadania dos descendentes de africanos. Para os autores, diante da importância do papel social desempenhado pelos libertos e descendentes de africanos, os deputados sabiam que não era possível criar critérios de exclusão baseados na herança do sangue africano, o que poderia prejudicar o sistema escravista.

Uma questão importante de se destacar em relação ao artigo da Constituição que definia quem eram os cidadãos brasileiros, é a inclusão de todos os libertos à condição de cidadãos, fato este que, segundo Andréa Slemian (2005), foi uma solução liberal inovadora:

\footnotetext{
${ }^{10}$ Sobre a outorga da Constituição de 1824, conferir: VAINFAS, 2002; MARQUESE \& BERBEL, 2007.
} 
A decisão, que era atualíssima do ponto de vista liberal e constitucional, reforçava, em seu contexto, a distinção entre o mundo dos homens livres e dos escravos e visava, na concepção normativa da maioria dos que compuseram a Assembleia, a manutenção da estabilidade desse sistema. Isso porque a existência de uma sociedade escravista no Brasil, onde mesmo os mais pobres possuíam - ou almejavam possuir - escravos, mesclada a não desprezível possibilidade de obtenção de alforrias, sobretudo durante o século XIX, faria que fosse vislumbrada como atraente a alternativa da liberdade individual pelos escravos que, num novo contexto constitucional, passariam a ser considerados cidadãos (p. 847).

Esta inclusão também dos libertos à condição de cidadãos se deu uma vez que a Constituição de 1824 concedia pelo menos os direitos civis a todos os indivíduos considerados cidadãos brasileiros. Vale dizer, que também considerou como brasileiros os portugueses que tivessem permanecido no país após a Independência e que tivessem aderido à "causa do Brasil", além dos estrangeiros naturalizados. Desta forma, estavam excluídos do direito de ser cidadão brasileiro os escravos, os libertos africanos, as mulheres e os indígenas (CONSTITUIÇÃO, 1824). Assim, considerar que todos os brasileiros eram cidadãos civis significava acenar com a possibilidade de um dia vir a exercer a cidadania política, para a qual era preciso possuir uma determinada renda. Então, os cidadãos brasileiros foram diferenciados, conforme Hebe Mattos (2000), a partir de direitos políticos por meio de critérios censitários, entre: cidadãos passivos e cidadãos ativos (p. 20-21). Ou seja, possuíam acesso a todos os direitos apenas aqueles que tivessem renda suficiente para participar diretamente do jogo eleitoral.

As eleições eram realizadas em dois graus, onde votantes escolhiam eleitores, que por sua vez escolhiam deputados e senadores. Assim, os cidadãos brasileiros que tivessem "renda liquida annual de cem mil réis por bens de raiz, industria, commercio, ou Empregos", poderiam votar nas Assembléias paroquiais, que escolhiam os eleitores de província. $\mathrm{Na}$ segunda etapa, "os libertos" e todos "os que não tiverem de renda liquida annual duzentos mil réis por bens de raiz, industria, commercio, ou emprego" ", estavam excluídos da votação.

Assim como a Constituição de 1811 da Venezuela, a Constituição de 1824 do Brasil se baseou na ideia da sociedade como naturalmente desigual, onde apenas alguns indivíduos tinham o acesso a todos os direitos de cidadãos. Apenas os que tivessem renda poderiam exercer seu direito de voto, participar diretamente do jogo eleitoral, ou seja, possuir todos os direitos. Essas restrições, como já apontado por alguns autores citados, foram uma tentativa de manter a estratificação da sociedade, sem realizar muitas modificações.

\footnotetext{
${ }^{11}$ Sobre as condições para ser eleitor, ver: Título 4, "Do Poder Legislativo", Capítulo VI, "Das Eleições" (Artigos 90 a 97) (CONSTITUIÇÃO, 1824).
} 


\section{Considerações finais}

Procuramos ressaltar que as características das Constituições da Venezuela e do Brasil, em relação às questões da cor da pele e da cidadania, trazem pontos semelhantes e divergentes. Observamos, por exemplo, que os processos de elaboração das Constituições de Venezuela e do Brasil estiveram inseridos em contextos diferentes. Na Venezuela, a primeira Constituição foi proclamada em 1811, no mesmo período em que se tentou proclamar a independência do país, mas não ficou em vigor por muitos anos, já que em 1830 a Venezuela aprovou a sua segunda constituição. Já a Constituição de 1824 do Brasil foi outorgada após a independência política do país, ficando em vigor durante todo o período imperial.

A idéia de uma sociedade desigual marcou as duas Constituições, assim como as de outros países da América, onde, como afirma Miriam Dolhnikoff:

Inclusão e exclusão conformaram estas experiências, e, neste contexto, a
construção da cidadania foi um processo pelo qual uma gama de indivíduos
passou a gozar de direitos políticos, sem que, contudo, isto tivesse uma
perspectiva universalizante como nas democracias modernas
(DOLHNIKOFF, 2009, p. 42).

Tanto na Venezuela quanto no Brasil, a partir das Constituições alguns indivíduos passaram a ser considerados cidadãos, e alguns também puderam exercer seus direitos políticos, mas isto ocorreu de maneiras distintas. Na Constituição de 1811 da Venezuela, as leis que impunham impedimentos aos pardos foram revogadas, o que permitiu que estes indivíduos passassem a ser considerados cidadãos. A existência de um artigo específico que passou a considerar apenas os pardos como cidadãos venezuelanos e de um artigo que excluía os que haviam sofrido infâmia que não tinha sido retirada da lei, nos permite compreender que os considerados cidadãos plenos, isto é, com acesso aos direitos civis e políticos (se possuíssem a renda exigida), eram os brancos e os pardos livres.

A Constituição de 1824 do Brasil, diferente da Venezuela, possuía um artigo específico que definia quem eram os cidadãos brasileiros, sem mencionar a cor da pele. Mas a existência do critério censitário contribuiu para excluir da participação política a maior parte da população de cor livre. Enfim, como discutido ao longo do artigo, em ambos os contextos havia a busca por uma estabilidade para o país que, na prática, significava não alterar a estrutura da sociedade e manter o sistema escravista.

Em relação ao direito de voto, ambas se baseavam no critério censitário, ou seja, apenas quem tivesse renda podia participar do jogo político, possuindo, assim, todos os direitos. Baseavam-se então na idéia, presente também nas outras partes das Américas, 
conforme Dolhnikoff, de que era necessário que apenas aqueles com melhor "discernimento" pudessem eleger e ser eleito, só os que fossem qualificados:

o representante de qualidade seria escolhido se o voto fosse exclusivo de eleitores também qualificados. A consequente limitação de setores da população que participariam do jogo político através do voto era tida como virtuosa, da mesma forma que no XX, inversamente, se considerará virtuosa a expansão do eleitorado (DOLHNIKOFF, 2009, p. 42).

As eleições foram o mecanismo para o acesso ao poder político, conforme Hilda Sabato: "os representantes deviam ser os melhores para encarnar a vontade ou a razão coletiva, e as eleições, o método apropriado para selecionar quem era definido como apto" (SABATO, 2009, p. 10).

Outra questão importante é o fato de ambas as Constituições não fazerem referência aos escravos em seus textos. O escravo era tido como coisa, como propriedade, ou seja, não fazia parte da sociedade civil, conforme Dolhnikoff (2009), "na concepção de cidadania política prevalecente no XIX a exclusão do escravo não era um problema (...). O escravo estava fora da sociedade civil e, portanto, não cabia considerá-lo como membro da sociedade política" (p. 45). Vale dizer, que na Constituição de 1811 da Venezuela o capítulo nono traz o artigo 202, sobre a proibição do comércio de escravos: "El comercio inicuo de negros prohibido por decreto de la Junta Suprema de Caracas, en 14 de agosto de 1810, queda solemnemente abolido en todo el territorio de la unión, sin que puedan de modo alguno introducirse esclavos de ninguna especie por vía de especulación mercantil" (CONSTITUCIÓN, 1811). Mas, sabe-se que não se efetivou, uma vez que o tráfico de escravos só foi abolido na Venezuela em 1823. Na Constituição de 1824 do Brasil, não há referência ao tráfico de escravos. Conforme já citado ao longo do artigo, havia uma grande preocupação nos dois contextos em não abalar o sistema escravista.

Outro ponto relevante sobre as Constituições é o fato de que as duas sancionaram a separação de poderes: legislativo, executivo e judiciário, sendo que no Brasil, devido à opção monárquica de governo, ainda havia o poder moderador, que pertencia ao Imperador. Ambas estabeleceram que todos os cidadãos teriam direitos aos empregos públicos, aboliram o uso da tortura, estabeleceram o direito de manifestar os pensamentos pela imprensa, além de oficializar a religião católica como a oficial do Estado, dentre outros aspectos.

Enfim, estas distintas experiências constitucionais enfrentaram questões parecidas e vivenciaram-nas conforme suas particularidades. As duas Constituições se basearam na questão de que deveria prevalecer um sistema em que os "melhores", os "mais capacitados", definiriam os interesses nacionais; e a definição desse sistema foi profundamente marcada 
pela relação entre cidadania e cor da pele. Contudo, também não podemos deixar de observar que um grupo maior de pessoas passou a ser considerados cidadãos.

\section{Fontes}

CONSTITUCIÓN Federal de 1811. Disponível em:http://www.cervantesvirtual.com/servlet/SirveObras/02461621981246052976613/index.ht m. Acesso em: 08/12/2016.

CONSTITUIÇÃO Política do Imperio do Brazil (de 25 de março de 1824). Disponível em:http://www.planalto.gov.br/ccivil_03/constituicao/constitui\%C3\%A7ao24.htm. Acesso em: 08/12/2016.

DECLARACIÓN de los derechos del pueblo de 1811. Disponível em:

http://www.cervantesvirtual.com/portales/constituciones_hispanoamericanas/obravisor/declaracion-de-los-derechos-del-pueblo-de-1811/html/07ae10e4-f450-41ba-a3fb8fb7cd0e4bec_2.html\#I_0_. Acesso em: 15/12/2016.

\section{Referências bibliográficas}

AZEVEDO, Célia Marinho. A recusa da "raça": anti-racismo e cidadania no Brasil dos anos 1830. Horizontes Antropológicos, v. 11, n. 24, p. 297-320, 2005.

CARVALHO, José Murilo. Cidadania no Brasil: o longo caminho. $2^{\mathrm{a}}$ edição. Rio de Janeiro: Civilização Brasileira, 2002.

CHIARAMONTE, José Carlos. As formas de identidade política no final do vice-reinado. In: Cidades, Províncias, Estados. São Paulo: Hucitec, 2009.

DOLHNIKOFF, Miriam. Representação na monarquia brasileira. In: Almanack Braziliense, $\mathrm{n}$. 09, 2009.

GÓMEZ, Alejandro E. Las revoluciones blanqueadoras: elites mulatas haitianas y "pardos beneméritos" venezolanos, y su aspiración a la igualdad, 1789-1812. In: Nuevo Mundo Mundos Nuevos, Coloquios, 2005, [En línea], Puesto en línea el 19 marzo 2005. URL: http://nuevomundo.revues.org/868. Consultado el 06 diciembre 2010.

GREENE, Jack P. \& MORGAN, Philip. Atlantic History: A critical appraisaal. Paperback, 2009.

LARA, Silvia Hunold. Fragmentos setecentistas: escravidão, cultura e poder na América portuguesa. São Paulo: Companhia das Letras, 2007.

MAIA, Iara de. Os designativos de cor no Império do Brasil: Mariana, 1824-1850. Dissertação (Mestrado em História). Universidade Federal de Ouro Preto, Ouro Preto, 2012.

MARQUESE, Rafael; BERBEL, Márcia Regina. A ausência da raça: escravidão, cidadania e ideologia pró-escravista nas Cortes de Lisboa e na Assembléia Constituinte do Rio de Janeiro (1821-1824). In: CHAVES, Cláudia Maria das Graças; SILVEIRA, Marco Antonio (orgs.). Território, conflito e identidade. Belo Horizonte, MG: Argvmentvm; Brasília, DF: CAPES, 2007.

MARQUESE, Rafael; BERBEL, Márcia Regina; PARRON, Tâmis. Escravidão e política. Brasil e Cuba, c.1790-1850. São Paulo: Hucitec, 2010.

MATTOS, Hebe. A escravidão moderna nos quadros do Império português: o Antigo Regime em perspectiva atlântica. In: FRAGOSO, João; BICALHO, Maria Fernanda; GOUVÊA, 
Maria de Fátima (orgs.). O Antigo Regime nos trópicos: a dinâmica imperial portuguesa (séculos XVI - XVIII). Rio de Janeiro: Civilização Brasileira, 2001.

2000.

Escravidão e cidadania no Brasil Monárquico. Rio de Janeiro: Jorge Zahar. Ed.,

QUINTERO, Inés. A independência da Venezuela: resultados políticos e alcances sociais. In: PAMPLONA, Marco A.; MADER, Maria Elisa (org.). Revoluções de independência e nacionalismos nas Américas: Nova Granada, Venezuela e Cuba. São Paulo: Paz e Terra, 2009.

SABATO, Hilda. Soberania popular, cidadania e nação na América Hispânica: a experiência republicana do século XIX. In: Almanack Braziliense, n 09, maio 2009.

SILVA, Luiz Geraldo. Afrodescendentes livres e libertos e igualdade política na América portuguesa. Mudança de status, escravidão e perspectiva atlântica (1750-1840). Almanack, p. 571-632, 2015.

SLEMIAN, Andréa. Os canais de representação política nos primórdios do Império: apontamentos para um estudo da relação entre Estado e sociedade no Brasil (c.1822-1834). Revista Locus, v. 13, n.I, p. 34-51, 2007.

Seriam todos cidadãos? Os impasses na construção da cidadania nos primórdios do constitucionalismo no Brasil (1823-1824). In: JANCSÓ, István (org.). Independência: história e historiografia. São Paulo: Hucitec: Fapesp, 2005.

Sob o império das leis: Constituição e unidade nacional na formação do Brasil (1822-1834). São Paulo: Aderaldo \& Rothschild: Fapesp, 2009.

THIBAUD, Clément. Definiendo el sujeto de la soberania: repúblicas y guerra em la Nueva Granada y Venezuela, 1808-1820. In: CHUST, Manuel y MARCHENA, Juan (eds.). Las armas dela nación. Independencia y ciudadanía en Hispanoamérica (1750-1850). Iberoamericana, Madrid, 2007.

VAINFAS, Ronaldo (org.). Dicionário do Brasil Imperial. Rio de Janeiro: Objetiva, 2002. Verbete: Constituição. 